\title{
Analisis Saluran dan Margin Pemasaran Bunga Potong Anthurium di Desa Candikuning, Kecamatan Baturiti, Kabupaten Tabanan
}

\author{
FAQIH HASMURULLAH, I NYOMAN GEDE USTRIYANA, \\ I GAA LIES ANGGRENI \\ Program Studi Agribisnis, Fakultas Pertanian, Universitas Udayana \\ Jl. PB Sudirman Denpasar 80232 \\ Email: faqih.kulminasi@gmail.com \\ komingbudi@yahoo.com
}

\begin{abstract}
This study aimed to determine the pattern of marketing channels, marketing margin of each marketing channel of anthurium cut flowers in the village of Candikuning and problems faced by anthurium cut flowers farmers in marketing their products. Basic method of this research was descriptive qualitative and quantitative. The research area was taken purposively, that is, Candikuning Village, Baturiti Dustrict, Tabanan Ragency. The method to determine the sample of respondents used census method for farmers, because out of the farmers of anthurium cut flowers in the Village of Candikuning there were eight farmers and snowvall sampling for marketing agencies. The data ware taken either in the form of primary data and secondary data through interviewing, recording and observation. The research result showed that there were two patterns of anthurium cut flower marketing channels in Candikuning Village i.e., channel I : Farmers $\rightarrow$ Village Collectors $\rightarrow$ Retailer Trades $\rightarrow$ Consumers, channel II : Farmers $\rightarrow$ Retailer Trades $\rightarrow$ Consumers. The highest marketing margin was in the first pattern i.e. IDR 3.000 per stalk, for the pattern II amounted to IDR 2.500 per stalk. The higest share received by the farmers was in the marketing pattern II i.e. $37,5 \%$. The problems faced by anthurium cut flower farmers in marketing their products were the price of anthurium flowers in yhe faremr level was low.
\end{abstract}

Keywords: flowers, marketing, margins, channel

\section{Pendahuluan}

\subsection{Latar Belakang}

Indonesia yang merupakan negara tropis mempunyai dataran rendah dan dataran tinggi, sehingga memungkinkan hampir semua jenis komoditas florikultura dapat diusahakan. Usaha tanaman hias di Indonesia dapat dilakukan dan dipanen sepanjang tahun tanpa terganggu musim sehingga kontinuitas dapat terus terpenuhi untuk memenuhi permintaan pasar. Permintaan bunga di Indonesia mengalami fluktuasi sepanjang tahun. Permintaan bunga meningkat 20-30 kali dari pada biasanya, yaitu pada bulan-bulan ramai seperti natal dan tahun baru, imlek, valentine, lebaran, hari kemerdekaan, dan bulan-bulan penyelenggaraan perkawinan (Abidin dan Rosana, 2001). 
Salah satu produk bunga potong adalah anthurium, bunga potong anthurium merupakan salah satu tanaman hias hasil produk florikultura yang telah banyak dibudidayakan petani dan menjadi sumber usaha. Desa Candikuning merupakan salah satu desa penghasil bunga potong anthurium di Kecamatan Baturiti, terdapat delapan petani bunga potong anthurium di wilayah tersebut. Berdasarkan data dari Dinas Pertanian Tanaman Pangan dan Hortikultura Kabupaten Tabanan, terjadi peningkatan produksi bunga potong anthurium di Kecamatan Baturiti, yaitu produksi bunga potong anthurium pada tahun 2010 sebanyak 250.400 tangkai meningkat menjadi 443.000 tangkai pada tahun 2014. Peningkatan produksi menunjukan bahwa Kabupaten Tabanan merupakan daerah yang potensial untuk mengembangkan komoditi bunga potong anthurium guna memenuhi permintaan pasar.

Pemasaran bunga potong anthurium di Desa Candikuning melibatkan beberapa lembaga pemasaran, dimana tiap lembaga memiliki kemungkinan melakukan fungsi pemasaran untuk menjaga kualitas bunga potong anthurium yang akan dijual. Menurut Swastha (1979) bahwa kegiatan saluran distribusi (pemasaran) merupakan suatu tindakan ekonomi yang mendasarkan pada kemampuannya untuk membantu dalam penciptaan nilai ekonomi. Pemasaran bunga potong anthurium di Desa Candikuning melibatkan beberapa lembaga pemasaran tentu akan terjadi margin pemasaran pada tiap lembaga pemasaran yang terlibat dan berakibat terjadinya perbedaan harga di tingkat konsumen akhir dengan harga di tingkat produsen (petani). Menurut Rahim dan Hastuti (2007) bahwa margin pemasaran suatu komoditas dipengaruhi oleh berbagai aspek, yaitu jenis produk, jumlah pelaku pasar, mekanisme perdagangan, infra struktur, kebijakan pemerintah dan waktu. Pemasaran menjadi hal yang penting dalam menjalankan kegiatan usaha tani bunga potong anthurium, karena merupakan tindakan ekonomi yang berpengaruh terhadap tinggi rendahnya pendapatan petani. Pemasaran akan berjalan baik dan efektif apabila informasi pemasaran bunga potong anthurium diketahui, kurangnya informasi pasar anthurium menjadi sebab tanaman anthurium ini masih menjadi tanaman sampingan yang kurang digemari oleh petani Desa Candikuning.

Uraian tersebut telah menjelaskan bahwa pemasaran bukan sesuatu yang sederhana akan tetapi kompleks. Pentingnya analisis saluran dan margin pemasaran adalah untuk mengetahui sejauh mana sistem pemasaran produk bunga potong anthurium memberi kontribusi keuntungan paling besar dalam pendapatan petani sehingga layak untuk diusahakan dan juga untuk mengetahui informasi atau kondisi pasar bunga potong anthurium di pasaran saat ini.

\subsection{Tujuan Penelitian}

Tujuan penelitian ini adalah untuk mengetahui tiga hal pokok sebagai berikut.

1. Mengetahui saluran pemasaran bunga potong anthurium yang dilakukan oleh petani bunga potong anthurium di Desa Candikuning.

2. Menganalisis margin pemasaran diantara lembaga pemasaran yang terlibat dalam pemasaran bunga potong anthurium. 
3. Mengetahui permasalahan yang dihadapi petani bunga potong anthurium yang ada di Desa Candikuning dalam memasarkan produknya.

\section{Metode Penelitian}

\subsection{Lokasi dan Waktu Penelitian}

Penelitian dilaksanakan di Desa Candikuning, Kecamatan Baturiti, Kabupaten Tabanan. Penelitian ini dilakukan dari bulan januari s.d maret 2016. Penentuan lokasi penelitian ini dilakukan secara purposive sampling yaitu cara penetapan lokasi secara sengaja atau atas dasar pertimbangan-pertimbangan tertentu. Pertimbangan yang digunakan dalam pemilihan lokasi penelitian ini sebagai berikut a. Desa Candikuning sebagai daerah penghasil bunga potong anthurium yang ada di Kabupaten Tabanan $b$. Petani bunga potong anthurium di Desa Candikuning sebagian besar belum mengetahui informasi pasar (harga) bunga potong anthurium di pasar bunga (konsumen) c. Sejauh ini belum pernah ada dilakukan penelitian sejenis di Desa Candikuning.

\subsection{Penentuan Responden Penelitian}

Populasi adalah jumlah dari anggota sampel secara keseluruhan, dimana di dalam populasi tersebut mereka mempunyai kesempatan yang sama untuk dipilih sebagai sampel. Sampel (responden) adalah sebagian dari anggota populasi yang terpilih sebagai obyek pengamatan (Shinta, 2011). Penentuan petani sampel dilakukan dengan menggunakan metode sensus (pengambilan sampel dari keseluruhan populasi), karena petani bunga potong anthurium di Desa Candikuning terdapat delapan petani bunga potong anthurium, sedangkan penentuan sampel lembaga pemasaran bunga potong anthurium menggunakan metode snowball sampling yaitu penelusuran saluran pemasaran bunga potong anthurium yanga ada di Desa Candikuning mulai dari produsen sampai konsumen akhir berdasarkan informasi yang diberikan produsen.

\subsection{Teknik Pengumpulan Data, Variabel Penelitian, dan Metode Analisis}

Data kualitatif merupakan data yang berbentuk kata, kalimat, atau gambar dan data kuantitatif adalah data yang berbentuk angka atau data kualitatif yang diangkakan (Sugiono, 2008). Teknik pengumpulan data yang digunakan dalam penelitian ini adalah dengan melakukan observasi langsung ke tempat penelitian yaitu di Desa Candikuning. Wawancara, yaitu mengadakan tanya jawab langsung ke responden dengan menggunakan kuesioner. Dokumentasi, yaitu teknik pengumpulan data dengan cara mencari dokumentasi-dokumentasi resmi yang berhubungan dengan penelitian. Penelitian ini menggunakan tiga variabel, yaitu saluran dan margin pemasaran bunga potong anthurium dan masalah yang dihadapi petani dalam memasarkan bunga potong anthurium. Metode analisis yang digunakan dalam penelitian ini adalah analisis kualitatif dan kuantitatif. Analisis data dalam penelitian ini menggunakan :

1. Analisis $\mathrm{R} / \mathrm{C}$ ratio yaitu :

Untuk menemukan nilai R/C ratio menggunakan rumus (Soekartawi, 1987): 


$$
\mathrm{R} / \mathrm{C} \text { ratio }=\frac{T \mathrm{R}}{\mathrm{TC}}
$$

Dengan kriteria :

$\mathrm{R} / \mathrm{C}>1$ berarti usaha tersebut sudah efisien dan menguntungkan

$\mathrm{R} / \mathrm{C}=1$ berarti usaha tersebut impas (tidak untung dan tidak rugi)

$\mathrm{R} / \mathrm{C}<1$ berarti usaha tersebut merugi dan tidak efisien

2. Analisis Margin Pemasaran bunga potong anthurium.

Secara matematis margin pemasaran dirumuskan sebagai berikut (Sudiyono, 2002) :

$$
\mathrm{MP}=\operatorname{Pr}-\mathrm{Pf}
$$

Keterangan :

MP : Margin pemasaran

Pr : Harga tingkat di pengecer (harga yang dibayarkan konsumen akhir)

Pf : Harga tingkat di petani

Keuntungan lembaga pemasaran :

$$
\underset{\mathrm{Ki}=\mathrm{Hji}-\mathrm{Hbi}-\Sigma \text { Bpi }}{\mathrm{S}=1}
$$

Keterangan :

Hji : Harga jual lembaga pemasaran ke -i

Hbi : Harga beli lembaga pemasaran ke-i

Bpi : Biaya pemasaran lembaga pemasaran ke-i

$\mathrm{m} \quad$ : Jumlah jenis biaya

$\mathrm{s} \quad$ : Jenis biaya pemasaran

Bagian keuntungan dan biaya pemasaran masing-masing lembaga pemasaran

$$
\begin{aligned}
& \mathrm{SKi}=\frac{K i}{\mathrm{Pr}-\mathrm{Pf}} \times 100 \% \\
& \mathrm{SBi}=\frac{\mathrm{Bi}}{\mathrm{Pr}-\mathrm{Pf}} \times 100 \%
\end{aligned}
$$

Keterangan :

SKi : Bagian keuntungan lembaga pemasaran i

$\mathrm{SBi}$ : Bagian biaya fungsi pemasaran lembaga pemasaran i

Besarnya bagian atau share yang diterima petani (SP) dari harga eceran dapat dihitung dengan menggunakan:

$$
\mathrm{SP}=\frac{\mathrm{Pf}}{\mathrm{Pr}} \times 100 \%
$$

\section{Hasil dan Pembahasan}

\subsection{Karekteristik Budidaya Bunga Potong Anthurium}

Bunga potong anthurium di Desa Candikuning merupakan komoditi sampingan yang dibudidayakan oleh petani yang komoditi utamanya adalah sayuran dataran tinggi maupun oleh wiraswasta yang pekerjaan utamanya dipelayanan jasa seperti tempat laundry, bengkel (montir) dan sopir boat di obyek wisata Danau Beratan dan 
pegawai kantoran di Kebun Raya Eka Karya Bali di Desa Candikuning, alasan mereka membudidayakan bunga potong anthurium karena bunga potong anthurium merupakan warisan dari orang tuanya dan bunga potong anthurium tidak sulit untuk dibudidayakan, mudah dalam perawatan tanaman, biaya produksi yang terjangkau atau rendah dan tidak perlu lahan yang luas serta yang paling utama untuk menambah pendapatan keluarga setiap bulannya. Sebagian besar petani dalam membudidayakan tanaman bunga potong anthurium memanfaatkan pekarangan rumahnya sebagai tempat budidaya tanaman anthurium, yang luas pekarangan rumahnya antara 1,5 are sampai dengan 2 are dengan jumlah bibit tanaman 1.000 per are.

\subsection{Identitas Responden}

\section{Petani reponden}

Berdasarkan data primer yang dikumpulkan dalam penelitian ini, karakteristik petani responden yang dibahas dapat dikelompokan berdasarkan ciri-ciri tertentu yang dimiliki seperti umur, tingkat pendidikan formal, pengalaman berusahatani dan luas lahan tanam bunga potong anthurium. Hasil penelitian menunjukan bahwa kisaran umur responden yang melakukan usaha budidaya bunga potong anthurium adalah pada umur 35 sampai dengan 54 tahun. Hal ini menunjukan bahwa responden yang mengusahakan budidaya bunga potong anthurium berada pada usia produktif (15-64 tahun). Tingkat pendidikan formal responden digolongkan memiliki pendidikan yang cukup tinggi yaitu, $50 \%$ responden memiliki pendidikan tamatan SMA, $25 \%$ responden memiliki tingkat pendidikan tinggi seperti D3 dan S1. Pengalaman petani responden dalam berusahatani bunga potong anthurium digolongkan cukup lama yaitu, 62,5\% responden memiliki pengalaman berusahatani bunga potong anthurium 6-10 tahun dan $25 \%$ responden memilik pengalaman berusahatani bunga potong anthurium 11-15 tahun. Luas tanam bunga potong anthurium yang dimiliki petani digolongkan kecil, $50 \%$ responden memiliki luas tanam bunga potong anthurium kurang dari 1 are ini dikarenakan petani menyesuaikan luas pekarangan rumah yang dimiliki petani.

2. Responden lembaga pemasaran

Berdasarkan hasil penelitian ini diketahui responden lembaga pemasaran bunga potong anthurium meliputi pedagang pengepul (pengepul desa) dan pedagang pengecer (toko bunga). Berdasarkan data primer yang dikumpulkan dalam penelitian ini karakteristik responden lembaga pemasaran bunga potong anthurium yang di bahas dapat dikelompokan berdasarkan ciri-ciri seperti umur responden lembaga pemasaran, tingkat pendidikan dan pengalaman berdagang.

1. Pedagang pengepul (pengepul desa)

Umur responden pedagang pengepul (pengepul desa) bunga potong anthurium tergolong berada pada usia 46 sampai dengan 51 tahun, hal ini menunjukan responden berada pada usia produktif. Tingkat pendidikan responden pedagang pengepul (pengepul desa) dapat digolongkan cukup tinggi yaitu 66,67 
$\%$ pedagang pengepul tamatan SMA. Pengalaman berdagang responden dapat digolongkan cukup lama yaitu selama 10 tahun.

2. Pedagang pengecer (toko bunga)

Umur responden pedagang pengecer (toko bunga) bunga potong anthurium tergolong berada pada usia 48 sampai dengan 53 tahun, hal ini menunjukan responden berada pada usia produktif. Tingkat pendidikan responden pedagang pengecer (toko bunga) dapat digolongkan cukup tinggi yaitu 66,67\% pedagang pengecer tamatan SMA dan 33,33 \% tamatan S1. Pengalaman berdagang responden dapat digolongkan sangat lama yaitu selama 20 tahun.

\subsection{Saluran Pemasaran}

Kotler (1987), mendefinisikan saluran pemasaran merupakan suatu saluran distribusi (channel of distribution) dianggap mencakup suatu kelompok lembagalembaga yang melaksanakan keseluruhan kegiatan (fungsi) untuk mengalihkan produk disertai hak miliknya dari lingkungan produksi ke arah lingkungan konsumsi. Berdasarkan hasil penelitian yang telah dilaksanakan terdapat dua saluran pemasaran bunga potong anthurium di Desa Candikuning, yaitu :

1. Petani --- Pengepul Desa --- Pedagang Pengecer (toko bunga) --- Konsumen

2. Petani --- Pedagang Pengecer (toko bunga) --- Konsumen

Adanya perbedaan saluran dan panjang pendeknya saluran pemasaran ini akan mempengaruhi tingkat harga, bagian keuntungan dan biaya, serta margin pemasaran yang diterima setiap pelaku pemasaran bunga potong anthurium.

\subsection{Margin Pemasaran}

Analisa margin pemasaran dapat digunakan untuk mengetahui margin pemasaran yang terdiri dari biaya dan keuntungan dari setiap aktifitas lembaga pemasaran yang berperan aktif, serta untuk mengetahui bagian harga (farmer share) yang diterima oleh petani dan juga untuk mengetahui efisiensi pemasaran. Lebih lanjut Saliem (2004) menyatakan bahwa tujuan analisis margin pemasaran bertujuan untuk melihat efisiensi pemasaran yang diindikasikan oleh besarnya keuntungan yang diterima oleh masing-masing pelaku pemasaran. Semakin tinggi proporsi harga yang diterima produsen, semakin efisien sistem pemasaran tersebut.

Margin pemasaran bunga potong anthurium merupakan perbedaan harga atau selisih harga produk di tingkat produsen dan konsumen. Saluran pemasaran I seperti yang terlihat pada tabel 1 dibawah ini : 
Tabel 1.

Margin Pemasaran Saluran I

\begin{tabular}{|c|c|c|c|c|c|c|}
\hline No. & Uraian & $\begin{array}{c}\text { Nilai } \\
\text { (Rp/tangkai) }\end{array}$ & $\begin{array}{c}\text { Margin } \\
\text { (Rp/tangkai) }\end{array}$ & $\begin{array}{c}\text { Distribusi } \\
\text { Margin } \\
(\%) \\
\end{array}$ & $\begin{array}{c}\text { Share } \\
\text { Harga } \\
(\%) \\
\end{array}$ & $\begin{array}{l}\mathrm{R} / \mathrm{C} \\
\text { Ratio }\end{array}$ \\
\hline & $\begin{array}{l}\text { Petani } \\
\text { a. Harga Jual }\end{array}$ & 1.000 & & & 25 & \\
\hline 2. & \begin{tabular}{ll}
\multicolumn{2}{l}{ Pengepul Desa } \\
a. Harga Beli \\
b. Transportasi \\
c. Pengangkutan \\
d. Penyusutan \\
e. Pengepakan \\
f. Total Biaya \\
g. Keuntungan \\
h. & Harga Jual \\
\end{tabular} & $\begin{array}{c}1.000 \\
111 \\
33,3 \\
50 \\
27,7 \\
222 \\
778 \\
2.000\end{array}$ & 1.000 & $\begin{array}{r}3,70 \\
1,11 \\
1,66 \\
0,92 \\
7,40 \\
25,92\end{array}$ & 25 & 4,5 \\
\hline 3. & $\begin{array}{l}\text { PedagangPengecer } \\
\text { (toko bunga) } \\
\text { a. Harga Beli } \\
\text { b. Sewa Kios } \\
\text { c. Listrik } \\
\text { d. TenagaKerja } \\
\text { e. Pengemasan } \\
\text { f. Total Biaya } \\
\text { g. Keuntungan } \\
\text { h. Harga Jual } \\
\end{array}$ & $\begin{array}{c}2.000 \\
222 \\
83,3 \\
433 \\
83,3 \\
821,6 \\
1.178 \\
4.000 \\
\end{array}$ & 2.000 & $\begin{array}{r}7,4 \\
2,7 \\
14,4 \\
2,7 \\
27,4 \\
39,3\end{array}$ & 100 & 2,4 \\
\hline & Margin & & 3.000 & 100,00 & & \\
\hline
\end{tabular}

Sumber : Analisis Data Primer, 2016.

Berdasarkan hasil analisis pada tabel 1 dapat diketahui bahwa saluran pemasaran I bisa dikatakan efisien dan menguntungkan karena nilai $\mathrm{R} / \mathrm{C}$ ratio pemasaran $>1$. Tabel 1 memperlihatkan nilai margin total di saluran pemasaran I Rp. 3000 per tangkai bunga anthurium. Hal ini disebabkan petani tidak mengeluarkan biaya pemasaran. Bagian keuntungan yang diterima oleh masing-masing lembaga pemasaran juga bervariasi, dimana bagian terbesar justru pada lembaga pemasaran akhir yaitu pedagang pengecer sebesar $50 \%$ dengan $\mathrm{R} / \mathrm{C}$ ratio sebesar 2,4 sedangkan petani hanya mendapatkan bagian $25 \%$, tingginya bagian keuntungan yang diperoleh pedagang pengecer berkaitan dengan mengeluarkan biaya pemasaran cukup tinggi. Pada saluran pemasaran I lembaga pemasaran bunga potong anthurium yang terkait adalah pengepul desa dan pedagang pengecer (toko bunga). 
Tabel 2.

Margin Pemasaran Saluran II

\begin{tabular}{|c|c|c|c|c|c|c|}
\hline No. & Uraian & $\begin{array}{c}\text { Nilai } \\
\text { (Rp/tangkai) }\end{array}$ & $\begin{array}{c}\text { Margin } \\
\text { (Rp/tangkai) }\end{array}$ & $\begin{array}{l}\text { Distribusi } \\
\text { Margin } \\
(\%)\end{array}$ & $\begin{array}{c}\text { Share } \\
\text { Harga } \\
(\%)\end{array}$ & $\begin{array}{l}\mathrm{R} / \mathrm{C} \\
\text { Ratio }\end{array}$ \\
\hline 1. & $\begin{array}{l}\text { Petani } \\
\text { a. Harga Jual } \\
\text { b. Penyusutan } \\
\text { c. Pengepakan } \\
\text { d. Angkut } \\
\text { e. Total biaya } \\
\text { f. Keuntungan }\end{array}$ & $\begin{array}{r}1.500 \\
50 \\
16,6 \\
11,1 \\
77,7 \\
1.422,3\end{array}$ & & $\begin{array}{r}2 \\
0,6 \\
0,4 \\
3,1 \\
56,9\end{array}$ & 37,5 & \\
\hline 2. & $\begin{array}{l}\text { Pedagang } \\
\text { Pengecer (toko } \\
\text { bunga) } \\
\text { a. Harga Beli } \\
\text { b. Sewa Kios } \\
\text { c. Pengangkutan } \\
\text { d. Listrik } \\
\text { e. Tenaga Kerja } \\
\text { f. Pengemasan } \\
\text { i. Total Biaya } \\
\text { j. Keuntungan } \\
\text { k. Harga Jual } \\
\end{array}$ & $\begin{array}{r}1.500 \\
222 \\
222 \\
83,3 \\
433,3 \\
83,3 \\
1.043,9 \\
1.456,1 \\
4.000\end{array}$ & 2.500 & $\begin{array}{r}8,8 \\
8,8 \\
3,3 \\
17,3 \\
3,3 \\
41,8 \\
58,3\end{array}$ & 62,5 & 2,4 \\
\hline & Margin & & 2.500 & 100,00 & & \\
\hline
\end{tabular}

Sumber : Analisis Data Primer, 2016.

Berdasarkan tabel 2 dapat diketahui bahwa pada saluran pemasaran II dikatakan efisien dan menguntungkan karena nilai $\mathrm{R} / \mathrm{C}$ ratio pemasaran $>1$. Pada saluran pemasaran II lembaga pemasaran yang terkait hanya pedagang pengecer (toko bunga). Pada saluran pemasaran ini, petani menjual langsung bunga potong anthuriumnya kepada pedagang pengecer di Kota Denpasar.

Pada saluran pemasaran bunga potong anthurium ini, margin pemasaran yang terjadi sebesar Rp 2.500 per tangkai dimana harga bunga potong anthurium ditingkat petani sebesar Rp 1.500 per tangkai. Harga jual ditingkat pengecer sebesar Rp 4.000 per tangkai bunga anthurium. Share atau bagian keuntungan dari masingmasing lembaga pemasaran tertinggi terdapat pada pedagang pengecer yaitu sebesar $62,5 \%$ dengan R/C ratio pemasarannya sebesar 2,4. Bagian petani (farmer's share) sebesar 37,5\%, walaupun share lebih rendah dari pada pedagang pengecer (toko bunga) petani mendapatkan keuntungan yang lebih besar dengan melakukan pola pemasaran II.

\subsection{Masalah Pemasaran Petani Bunga Potong Anthurium}

Masalah yang dihadapi petani bunga potong anthurium di Desa Candikuning adalah harga jual bunga potong anthurium yang rendah di tingkat petani dan kurang 
aktifnya petani dalam mencari informasi mengenai harga di tingkat konsumen serta mencari informasi saluran pemasaran yang lebih menguntungkan.

\section{Simpulan dan Saran}

4.1 Simpulan

1. Terdapat dua pola saluran pemasaran bunga potong anthurium di Desa Candikuning.

a. Petani $\rightarrow$ Pengepul Desa $\rightarrow$ Pedagang Pengecer (toko bunga) $\rightarrow$ Konsumen

b. Petani $\rightarrow$ Pedagang Pengecer (toko bunga) $\rightarrow$ Konsumen.

2. Margin pemasaran tertinggi terdapat pada pola pemasaran I yaitu Rp 3.000 per tangkai. Share yang diterima petani tertinggi pada pola pemasaran II yaitu 37,5 $\%$.

3. Masalah yang dihadapi petani bunga potong anthurium dalam memasarkan produknya adalah harga jual bunga potong anthurium yang rendah di tingkat petani dan kurang aktifnya petani dalam mencari informasi mengenai harga di tingkat konsumen.

\subsection{Saran}

1. Saling berbagi informasi antara petani bunga potong anthurium mengenai perkembangan harga bunga potong anthurium dan membentuk kelompok tani bunga potong anthurium.

2. Mengoptimalkan fungsi-fungsi pemasaran (nilai tambah) dari produk bunga potong anthurium dan mengoptimalkan saluran pemasaran yang memiliki tingkat efisien pemasaran yang paling tinggi.

\section{Ucapan Terimakasih}

Terimakasih kepada Seluruh Petani bunga potong Anthurium di Desa Candikuning serta seluruh supplier bunga potong anthurium di Desa Candikuning dan Owner toko bunga di Denpasar yang telah banyak membantu dalam memberikan informasi selama penulis mengadakan penelitian. Seluruh pihak yang telah memberikan pengarahan, bimbingan dan juga dukungan dalam penyelesaian penelitian dan penulisan e-jurnal ini. Semoga penelitian ini dapat bermanfaat sebagaiman mestinya.

\section{Daftar Pustaka}

Abidin, I.S. dan Rosana, A.H. 2001. Prospek Pengembangan Industri Bunga di Indonesia. (Makalah Seminar Tanaman Hias). Badan Penelitian dan Pengembangan Pertanian, Lembang.

Dinas Pertanian Tanaman Pangan dan Hortikultura Kabupaten Tabanan, 2015. Produksi Anthurium Bunga (Tangkai) Kabupaten Tabanan Tahun 2010-2014.

Kotler, P. 1987. Manajemen Pemasaran, Marketing Management, Analisis, Perencanaan dan Pengendalian. Erlangga : Jakarta. 
Rahim dan Hastuti, DRD. 2007. Ekonomika Pertanian (Pengantar, Teori dan Kasus). Penebar Swadaya : Jakarta.

Saliem, H.P. 2004. Analisis Margin Pemasaran : Salah Satu Pendekatan dalam Sistem Distribusi Pangan. Dalam Prospek Usaha dan Pemasaran Beberapa Komoditas Pertanian. Monograph Series No. 24. Pusat Penelitian dan Pengembangan Sosial Ekonomi Pertanian. Bogor.

Shinta, A. 2011. Ilmu Usahatani. Cetakan Pertama. UB-Press : Malang.

Soekartawi. 1987. Pembangunan Pertanian. Raja Grafindo Persada : Jakarta.

Sudiyono. Armand. 2002. Pemasaran Pertanian. UMM-Press : Malang.

Sugiono. 2008. Statistika untuk Penelitian. CV. Alfabeta : Bandung.

Swasta, Bashu. 1979. Asas-asas Marketing. Akademi Keuangan dan Bisnis. Yogjakarta. 